Authors: Stanisław Wrzesień, Michał Frant, Maciej Majcher

Title of article: „Numeryczna analiza charakterystyk wentylatora osiowego” („Numerical analysis of axial fan characteristics”)

Mechanik, Vol. 91, No. 7 (2018): pages 606-608

DOI: https://doi.org/10.17814/mechanik.2018.7.98

\title{
Numerical analysis of axial fan characteristics
}

\section{Numeryczna analiza charakterystyk wentylatora osiowego}

\author{
STANISŁAW WRZESIEŃ \\ MICHAK FRANT \\ MACIEJ MAJCHER *
}

The paper presents an analysis and comparison of basic characteristics of axial fans, both analytically and numerically. Such characteristics are: the characteristics of the total pressure, power and total efficiency as a function of the volumetric flow rate. The presented results showed significant quantitative and qualitative differences in the characteristics obtained by two methods. The usefulness of numerical methods in relation to the results of the initial analytical project was confirmed.

KEYWORDS: CFD, flow machines, characteristics of axial fans

Currently, axial axial construction solutions are being sought, which will increase their efficiency, which is directly related to EU Commission Regulation No. 327/2011 of 30 March 2011 on the implementation of Directive 2009/125/EC of the European Parliament and of the Council of the European Union. with regard to eco-design requirements for fans powered by an electric motor with power consumption from $125 \mathrm{~W}$ to $500 \mathrm{~kW}$. This is due to the large share of this group of machines in the emission of carbon dioxide [12]. Structural solutions of axial fans available on the Polish market in most cases do not meet the requirements for a minimum level of efficiency - their overall efficiency at nominal parameters varies within a wide range - from approx. 45 to approx. $75 \%$.

The process of designing fans is based on the use of analytical algorithms. Analytical methods, based on a number of simplifications, do not allow for a full capture of the real flow phenomena occurring in the axes of vane axial fans. This is the reason for the discrepancy between the theoretical and the actual performance of these flow machines (especially that the flow of the working medium belongs to the class of transient three-dimensional issues). Due to simplifications, however, preliminary gasodynamic designs can be made, which are the basis for improving the efficiency of axial fans.

The analysis of the state of the problem [8, 10, 13] indicates the important role of numerical methods in obtaining qualitative and quantitative results, convergent

\footnotetext{
* Dr hab. inż. Stanisław Wrzesień (stanislaw.wrzesien@wat.edu.pl), mjr dra inż. Michał Frant (michal.frant@wat.edu.pl), mgr inż. Macie Majcher (maciej.majcher@wat.edu.pl) - Wojskowa Akademia Techniczna
}

with the results of experimental tests, and in the verification of analytical axial fan designs. Such verification limits the number of experimental tests of fans to the necessary minimum and thus reduces the costs associated with design.

\section{Analytic algorithm}

For the numerical verification of the axial fan axial design, a fan was designed with a nominal overall pressure increase of $p_{\mathrm{t}}=400 \mathrm{~Pa}$ at a volumetric flow rate of $Q=5 \mathrm{~m}^{3} / \mathrm{s}$. The project was made using analytical algorithms available in the literature $[5,7,14,16]$, which directly result from the straight-line palisade model (fig. 1), which is an analytical model of an axial flow machine. The palisade together with the speed triangles corresponding to it illustrates the character of the two-dimensional flow without changing the direction at the inlet.

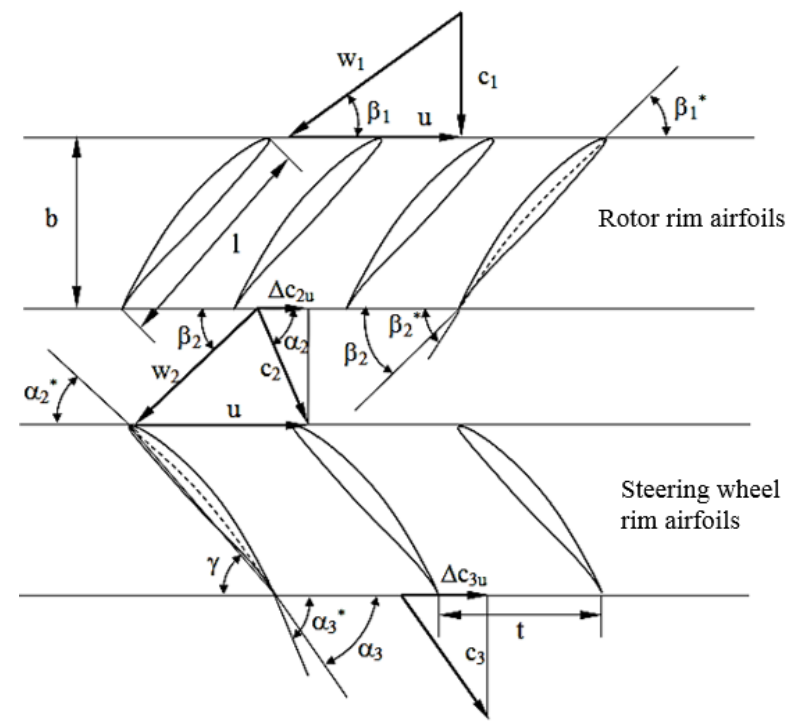

Fig. 1. Flat palisade of profiles

The geometry of the palisade is clearly defined by the applied profile, the length of its chord $I$, the pitch of the $t$ pitcher, the angle of the profile in the palisade $y$ and the width of the palisade $b$. Additionally, the so-called filling of the palisade $\sigma$, which is the ratio of the chord of the profile $I$ to the plot of the palisade $t$. Angles that form tangent to the skeleton profile in the geometric points of the leading and 
trailing edge in relation to the peripheral direction are called paddle angles [14].

The design process of the axial fan ends with determining the angles of setting the profiles in the palisade, their chords and the pitch of the palisade - both for rotor and steering rims - for defined nominal parameters. Fig. 2 shows the virtual model of the designed fan.

The advantages of the rectilinear palisade model include the simplicity of description of flow kinematics and the ability to estimate the performance of the designed fan. The key disadvantage is to bring the flow into the case of a fixed flat flow. There are also problems with estimating flow losses, including friction losses; the phenomenon of detachment or interference between the rotor and steering rim is also not taken into account.

Another important problem in the analytical design of paddle rims of axial flow machines is the selection of profiles for blades. The courses of aerodynamic factors, lift force and resistance force differ significantly for the cases of flow around insulated profiles and in the palisade [3, 4]. In the case of designing paddles for flow machines, coefficients for insulated profiles should not be used.

The problem of selecting profiles for paddle rims was solved thanks to the use of a function defining a skeleton parabolic-shaped coordinate [15]:

$$
y=\frac{x-x^{2}}{\frac{1-2 \cdot x_{f}}{f} \cdot x+\frac{x_{f}^{2}}{f}}
$$

Based on the axial fan design algorithm [15], the required deflection arrow $f$ was determined, which allowed to determine the skeleton shape of the profile, adapted to the obtained speed triangles. The NACA 65-010 [4] profile was used for the impeller and steering rims, for which the position of the maximum deflection arrow $x_{f}$ was provided on the half of the chord.

\section{Methodology of numerical analyses}

Numerical analysis of air flow through the axial fan blade system was performed using computer fluid mechanics methods implemented in the Ansys Fluent program for turbulent flow.

The turbulent flow can be treated as an average fixed motion [6]. It can therefore be concluded that the average flow parameters are constant over time despite the chaotic and pulsating nature of this movement. Taking this into account, the flow parameters can be represented as the sum of the mean (fixed) values and unsettled pulsations over time. Then, after appropriate transformations [6], an arrangement of Navier-Stokes averaged equations, known as Reynolds Averaged Navier (Stokes RANS) equations, can be written:

$$
\begin{gathered}
\frac{\partial \bar{u}_{\imath}}{\partial x_{i}}=0 \\
\frac{\partial}{\partial x_{j}}\left(\rho \bar{u}_{\imath} \bar{u}_{J}\right)= \\
\frac{\partial \bar{p}}{\partial x_{i}}+\frac{\partial}{\partial x_{j}}\left[\mu\left(\frac{\partial \bar{u}_{\imath}}{\partial x_{j}}+\frac{\partial \bar{u}_{J}}{\partial x_{i}}\right)\right]+ \\
-\frac{\partial}{\partial x_{j}}\left(\rho \bar{u}_{\imath} \bar{u}_{J}^{\prime}\right)
\end{gathered}
$$

In equation (2) one should pay attention to the segment $\frac{\partial}{\partial x_{j}}\left(\rho \bar{u}_{\imath} \bar{u}_{j}^{\prime}\right)$ which represents the stresses associated with the average velocity of momentum change caused by turbulent stresses.
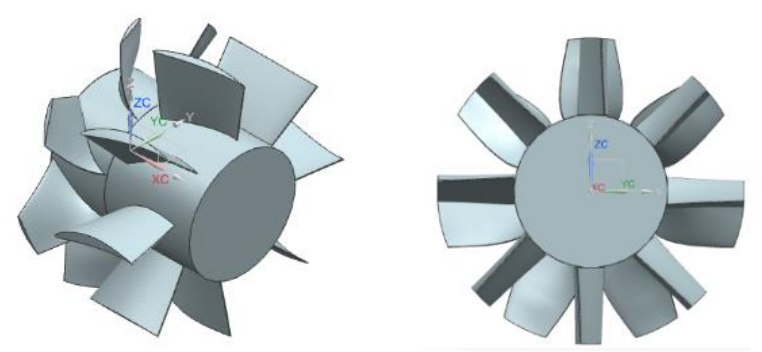

Fig. 2. Model of the designed fan

It is easy to see that the system of equations (2) is not a closed system. In order to close it, six equations describing the components of the tensor of turbulent stresses, which result from the turbulence model applied [9], should be added. A proven model is the previously implemented [9] realizable model $k-\varepsilon$ [1].

The closure of the system (2) also requires determining the dependence:

$$
p=p(\rho, T), \quad \mu=\mu(, T)
$$

\section{Numerical grids and boundary conditions}

For the needs of numerical analyzes, the model of the designed fan (fig. 2) was discretized in the Ansys software using the numerical model MRF (multiple reference frame), intended for multi-stage rotor machines [1].

Before starting numerical simulations, several grids were made for a single rotor ring, differing in the number of elements to analyze the influence of mesh density on the results obtained. The calculation models were digitized using the so-called hybrid meshes, typical for flow simulation through complicated shapes [2].

The basic characteristics of the fan operation are determined by numerical methods, with gradual throttling of the air flow through the fan. This is the same procedure as used in experimental tests at standardized stations [11] when determining fan performance. In the case of numerical analyzes, the throttling was achieved by changing the mass flow rate at the inlet, which is a standard in this type of analysis [1]. The boundary conditions typical for this type of computational cases were applied [8-10, 13].

The numerical results of the total pressure increase for the grids with different number of elements are summarized in the table. These data indicate that the number of finite elements has a negligible effect on simulation results (differences do not exceed $0.55 \%$ ).

Next, the courses of basic characteristics of the designed axial fan, obtained by numerical methods and analytically, were analyzed. The range of the expenditure for which the characteristics were made, the result of the computational range for the numerical model of the fan and the case of the steady flow.

TABLE. Results of total pressure increase for grids with different number of elements

\begin{tabular}{|c|c|}
\hline Number of grid elements & $\Delta \mathrm{p}_{\mathrm{c}}[\mathrm{Pa}]$ \\
\hline 1716434 & 446,08 \\
\hline 1637894 & 445,43 \\
\hline 1371790 & 447,55 \\
\hline 1196569 & 445,11 \\
\hline 865538 & 446,89 \\
\hline & \\
\hline
\end{tabular}




\section{Comparison of numerical and analytical results}

Fig. 3 shows the comparison of the characteristics of the total pressure increase for the designed fan, determined by analytical and numerical methods.

On the basis of the graphs shown, it can be concluded that the increase in analytically determined total pressure differs quantitatively from that obtained by numerical simulations. The smallest relative difference between the characteristics is $7.47 \%$ at an output of $5.5 \mathrm{~m} 3 / \mathrm{s}$. The average relative deviation in the range of $4.5 \div 7 \mathrm{~m} 3 / \mathrm{s}$ is $29.72 \%$. The difference in the characteristic curve results from the limitations of the analytical method and the inability to accurately assess flow losses. This fact also confirms the qualitative course of the characteristics. The analytical characteristic of the increase in total pressure in the range of the output of $4.5 \div 7 \mathrm{~m}^{3} / \mathrm{s}$ is linear, and the numerical characteristic is similar to the linear one. This is, among others effect of using a constant profile loss coefficient in the analytic algorithm. In fact, it is a function of the flow rate and the angle of inflow and runoff from the spatula (on its specific cross-section).

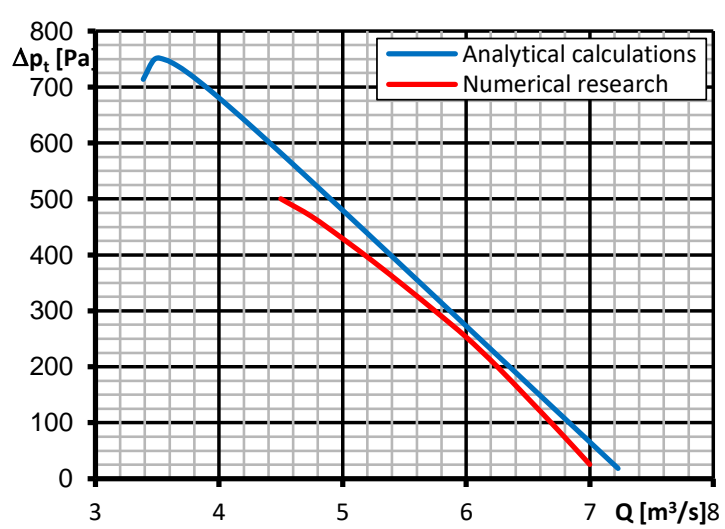

Fig. 3. Characteristic of the total pressure increase of the fan

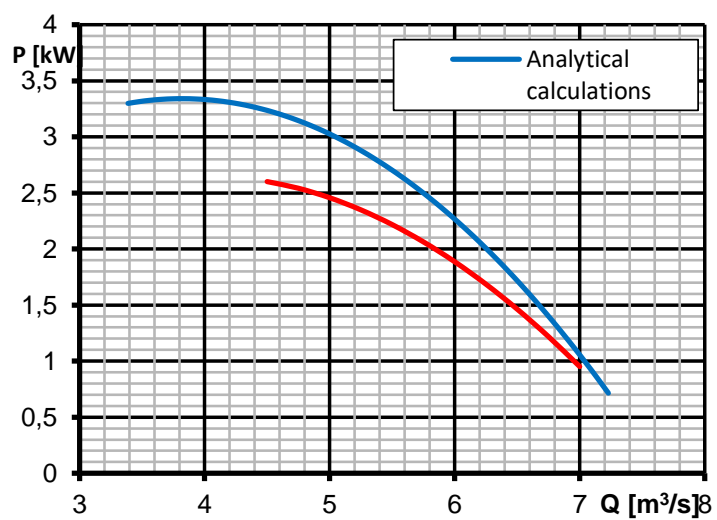

Fig. 4. Fan power characteristics with nominal parameters

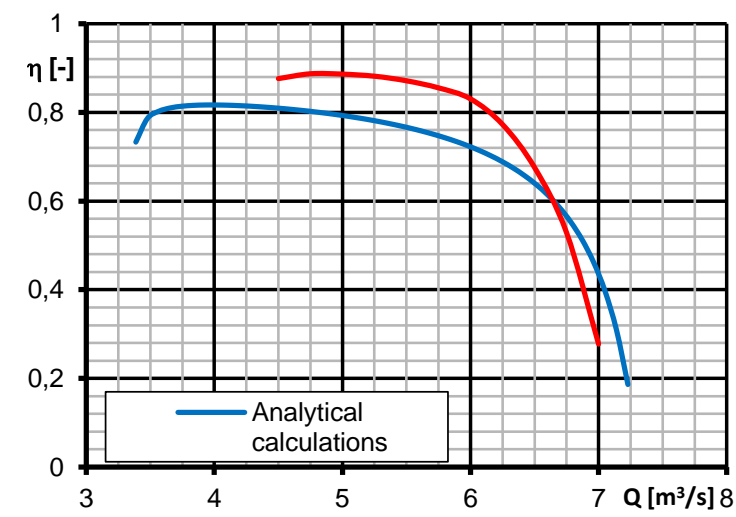

Fig. 5. Performance characteristics of the total fan
Fig. 4 shows the power characteristics. As you can see, the power calculated according to the analytical algorithm is overstated in relation to the power obtained by the numerical method. This is mainly due to the different ways of determining this parameter. The drive power determined by the analytical method consists in estimating the power necessary to overcome flow losses. In the numerical method, this power is determined on the basis of the resistance torque resulting from the influence of the working medium on the blade surface. The average relative deviation of the characteristics in the range of the output of $4.5 \div 7 \mathrm{~m}^{3} / \mathrm{s}$ is $20.27 \%$.

Fig. 5 shows the total efficiency characteristics. Visible differences between the characteristics result from the previously discussed differences in the fan power characteristics and the increase in total pressure as a function of the volumetric flow rate. The average relative deviation in the range of the output of $4.5 \div 7 \mathrm{~m}^{3} / \mathrm{s}$ is $14.9 \%$.

\section{Conclusions}

The paper presents a comparison of basic characteristics of an axial fan, obtained by analytical and numerical methods. The results obtained were discussed and significant differences in the performance of fans determined by these two test methods were demonstrated. The results confirm the necessity of verification of analytical fan designs using numerical methods. Knowledge of the level of discrepancies in results - both qualitative and quantitative - allows to specify the scope of work at the design stage of this type of machines, aimed at improving the efficiency of axial fans while maintaining the expected value of total compression and drive power.

\section{REFERENCES}

1. Ansys Fluent 12.0. User's Guide.

2. Ansys. Release 15. Meshing User's Guide.

3. Abbot I., Von Doenhoff A. "Theory of Wing Sections: Including a Summary of Airfoil Data". New York: Dover Publications INC 1959.

4. Emery J., Herrig J., Erwin J., Felix R. "Systematic twodimensional cascade tests of NACA 65-series compressor blades at low speed". NACA Technical Report 1368. USA: National Advisory Committee for Aeronautics. Langley Aeronautical Lab, 1958.

5. Fortuna S. „Wentylatory. Podstawy teoretyczne, zagadnienia konstrukcyjno-eksploatacyjne $i$ zastosowanie". Kraków: Techwent, 1999.

6. Kazimierski Z. „Podstawy mechaniki płynów i metod komputerowej symulacji przepływu", Łódź: Wydawnictwo Politechniki Łódzkiej, 2004.

7. Kuczewski S. „Wentylatory”. Warszawa: Wydawnictwa Naukowo-Techniczne, 1978.

8. Kumawat $\mathrm{H}$. "Modeling and simulation of axial fan using CFD". International Journal of Mechanical, Aerospace, Industrial, Mechatronic and Manufacturing Engineering. 8, 11 (2014): pp. 1892-1896.

9. Majcher M., Wrzesień S., Frant M. "The Impact of Mesh Quality and Mesh Adaptation on the Results of Numerical Solution of the Axial Fans". Summary of Proceedings. NAFEMS World Congress 2015, USA.

10. O`Halloran S., Hannukainen P., Makkonen P., Meyer L., Kumar V., Krosser M. "Fan Modeling Validation Using CFD". Summary of Proceedings. NAFEMS World Congress 2015, USA.

11. PN-EN ISO 5801:2008. Wentylatory przemysłowe - Badanie charakterystyk działania na stanowiskach znormalizowanych.

12. Rozporządzenie Komisji Unii Europejskiej nr 327/2011 z 30 marca $2011 \mathrm{r}$.

13. Sahili A., Zogheib B., Barron R. "3-D modeling of axial fans". Applied Mathematics. 04 (2013): pp. 632-651.

14. Tuliszka E. „Sprężarki, dmuchawy i wentylatory”. Warszawa: Wydawnictwa Naukowo-Techniczne, 1976.

15. Witkowski A. „Sprężarki wirnikowe. Teoria, konstrukcja, eksploatacja". Gliwice: Wydawnictwo Politechniki Śląskiej, 2013. 
Translation of scientific articles, their computer composition and publishing them on the website www.mechanik.media.p by original articles in Polish is a task financed from the funds of the Ministry of Science and Higher Education designated for dissemination of science. 